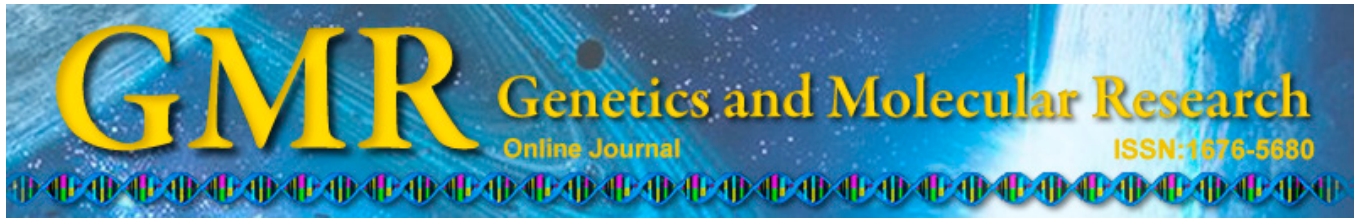

\title{
Genetic diversity analysis of sweet kernel apricot in China based on SSR and ISSR markers
}

\author{
M.P. Liu ${ }^{1,2}$, H.Y. Du ${ }^{1}$, G.P. Zhu ${ }^{1}$, D.L. Fu ${ }^{1}$ and W.Y. Tana ${ }^{1}$ \\ ${ }^{1}$ Non-Timber Forestry Research and Development Center, \\ Chinese Academy of Forestry, China Paulownia Research and Development Center, \\ Zhengzhou, He'nan, China \\ ${ }^{2}$ College of Food and Bioengineering, \\ Zhengzhou University of Light Industry, Zhengzhou, He'nan, China \\ Corresponding author: M.P. Liu \\ E-mail: mengpei0402@163.com
}

Genet. Mol. Res. 14 (3): 9722-9729 (2015)

Received January 8, 2015

Accepted May 8, 2015

Published August 19, 2015

DOI http://dx.doi.org/10.4238/2015.August.19.4

\begin{abstract}
Simple sequence repeat (SSR) and inter-simple sequence repeat (ISSR) markers were used to evaluate genetic diversity among 22 sweet kernel apricot accessions and 12 cultivars in China to provide information on how to improve the utilization of kernel apricot germplasms. The results showed that 10 pairs of SSR primers screened from 40 primer pairs amplified 43 allelic variants, all of which were polymorphic (100\%), and 9 ISSR primers selected from 100 primers amplified 67 allelic variants with 50 polymorphic bands $(74.63 \%)$. There was a relatively distant genetic relationship between the 34 samples, where their genetic similarity coefficient was between 0.62 and 0.99 . The UPGMA dendrogram constructed using combined data of the two marker systems separated the genotypes into three main clusters.
\end{abstract}

Key words: Kernel apricot; Simple sequence repeat; Genetic diversity; Inter-simple sequence repeat 


\section{INTRODUCTION}

Kernel apricot is one the six woody grain and oil strategic species. Among them, sweet kernel apricot is our unique economic species, which originated in Zhuolu, Hebei Province, China. The existing germplasm is less at present but has important economic value and prospects for wide utilization because of its thin endocarp, sweet kernels and sources of highquality oil. Its kernel oil is a healthy cooking oil. The unsaturated fatty acid content of the oil is about $95 \%$, and the monounsaturated fatty acid content of it is more than $70 \%$. At the same time, it is rich in proteins, vitamins, minerals, dietary fiber and trace elements required for the human body.

Genetic diversity analysis is essential for breeding, conservation and selection of appropriate genotypes of this important species. Molecular markers have been proven to be powerful tools. A variety of PCR-based DNA markers, such as random-amplified polymorphic DNA, microsatellite or simple sequence repeat (SSR), inter-simple sequence repeat (ISSR), amplified fragment length polymorphism, and sequence-related amplified polymorphism, provide the opportunity for fine-scale genetic characterizations, and still generate a large amount of data in a short period of time. Therefore, they are frequently used for genetic diversity assessment (Maguire et al., 2002; Gillaspie et al., 2005), variety identification (Hurtado et al., 1999; Bassil and Postman, 2010), genetic map construction (Piquemal et al., 2005; Celyon et al., 2008), pedigree analysis (Dreisigacker et al., 2004), etc.

SSR markers, also called microsatellite DNA markers or short tandem repeat markers are hypervariable DNA elements, which consist of tandemly repeated mono-, di-, tri-, tetra-, or pentanucleotide motifs. They are abundantly present in the genomes of higher organisms (Tautz et al., 1989). SSR markers have a number of advantages, such as the high level of polymorphisms, locus specificity, co-dominance, reproducibility, convenience through using PCR, and random distribution throughout the genome (Powell et al., 1997). As such, they have become a popular marker system in rice, wheat, almond, peach, and apple (Jain et al., 2004; Khlestkina et al., 2004; Xie et al., 2010; Garkava-Gustavsson et al., 2013). ISSR markers use primers based on di-, tetra-, or pentanucleotide sequence repeats and anchored nucleotides. These are randomly selected with the advantage of analyzing multiple loci in a single PCR and not requiring any prior information on the target sequence in the genome. They have been widely used in recent years in wheat, bean, firs, and tea (Hailu et al., 2005; Marotti et al., 2007; Zhang et al., 2007; Liu et al., 2010).

However, no information has been published concerning the genetic diversity of kernel apricot. The objectives of this study were to employ SSR and ISSR markers for investigation of genetic relationships and diversity between 22 sweet kernel apricot accessions and 12 cultivars in China. Comparisons were also made between the two molecular markers to assess their efficacy in determining the levels of genetic diversity.

\section{MATERIAL AND METHODS}

\section{DNA extraction}

Leaf samples of 22 sweet kernel apricot accessions and 12 cultivars were collected from Zhuolu (40 $\left.37^{\prime} \mathrm{N}, 115^{\circ} 2^{\prime} \mathrm{E}\right)$, Hebei Province and Luoyang $\left(34^{\circ} 39^{\prime} \mathrm{N}, 112^{\circ} 24^{\prime} \mathrm{E}\right)$, Henan Province, China (Table 1). Genomic DNA was extracted from leaf tissue by the cetyltrimeth- 
ylammonium bromide (CTAB) method as described by Saghai Maroof et al. (1984). The concentration of extracted DNA was estimated using $0.8 \%$ agarose gel electrophoresis. The samples were adjusted to $50 \mathrm{ng} / \mu \mathrm{L}$ and stored at $-20^{\circ} \mathrm{C}$ prior to $\mathrm{PCR}$ amplification.

\begin{tabular}{llcc}
\multicolumn{2}{l}{ Table 1. Origins of 22 sweet kernel apricot accessions and 12 cultivars in this study. } \\
\hline Identification & Origin & Identification & Origin \\
\hline Yiwofeng & HBZL & HB-18 & HBZL \\
Chaoren & HBZL & HB-19 & HBZL \\
Changchengyihao & HBZL & HB-20 & HBZL \\
$80 A 03$ & HBZL & HB-21 & HBZL \\
Youyi & HBZL & HN-22 & HBZL \\
Weixuanyihao & HBZL & HN-24 & HNLY \\
Sanganqi & HBZL & HN-25 & HNLY \\
Longwangmao & HBZL & HN-26 & HNLY \\
Fengren & HBZL & HN-27 & HNLY \\
Bokeyihao & HBZL & HN-28 & HNLY \\
Baiyubian & HBZL & HN-29 & HNLY \\
$79 C 13$ & HBZL & HN-30 & HNLY \\
HB-2 & HBZL & HN-33 & HNLY \\
HB-3 & HBZL & HN-34 & HNLY \\
HB-8 & HBZL & HN-35 & HNLY \\
HB-9 & HBZL & & HNLY \\
HB-15 & HBZL & HNLY \\
\hline
\end{tabular}

HBZL $=$ Zhuolu, Hebei Province; HNLY = Luoyang, Henan Province.

\section{Primer selection}

Initially, 40 pairs of SSR primers from Rosaceae universal primers and 100 ISSR primers [University of British Columbia (UBC), Vancouver, Canada (set \#9)] were tested with 12 samples for PCR amplification. On the basis of the maximum number and stability of polymorphic bands, 10 pairs of SSR primers and 9 ISSR primers were selected for further characterization of 34 genotypes.

\section{SSR and ISSR analysis}

SSR-PCR was performed in a $20-\mu \mathrm{L}$ reaction mixture containing $2.0 \mu \mathrm{L} 10 \mathrm{X}$ PCR buffer, $2.5 \mathrm{mM} \mathrm{MgCl}_{2}, 200 \mu \mathrm{M}$ of each dNTP, $1.5 \mathrm{U}$ Taq DNA polymerase, $0.5 \mu \mathrm{M}$ of each primer, and $50 \mathrm{ng}$ genomic DNA. The cycling parameters were programmed to 1 cycle of $94^{\circ} \mathrm{C}$ for $5 \mathrm{~min}, 35$ cycles of $94^{\circ} \mathrm{C}$ for $45 \mathrm{~s}$, optimal annealing temperature for $45 \mathrm{~s}$, and $72^{\circ} \mathrm{C}$ for $90 \mathrm{~s}$, followed by $72^{\circ} \mathrm{C}$ for $10 \mathrm{~min}$.

The products were separated by $8 \%$ polyacrylamide gel electrophoresis with $1 \mathrm{X}$ TBE buffer using Fluorescent Imaging Technology (Liu et al., 2011). The first procedure was that PCR products were mixed with $2 \mu \mathrm{L} 6 \mathrm{X}$ loading buffer containing Gelred dye in a PCR tube. It was then sampled and electrophoresed for $3 \mathrm{~h}$ at $120 \mathrm{~V}$ constant voltage. After washing the double-sided glasses, the gels were peeled, rinsed and placed in an ultraviolet analysis device (background, with glass board) for photographic analysis.

ISSR-PCR was performed in a $25-\mu \mathrm{L}$ reaction mixture containing $2.5 \mu \mathrm{L} 10 \mathrm{X}$ PCR buffer, $2.5 \mathrm{mM} \mathrm{MgCl} 2,200 \mu \mathrm{M}$ of each dNTP, $2.0 \mathrm{U}$ Taq DNA polymerase, $0.5 \mu \mathrm{M}$ of each primer, and $60 \mathrm{ng}$ genomic DNA. The cycling parameters were programmed to 1 cycle of 
$94^{\circ} \mathrm{C}$ for $5 \mathrm{~min}, 40$ cycles of $94^{\circ} \mathrm{C}$ for $60 \mathrm{~s}$, optimal annealing temperature for $60 \mathrm{~s}$, and $72^{\circ} \mathrm{C}$ for $120 \mathrm{~s}$, followed by $72^{\circ} \mathrm{C}$ for $10 \mathrm{~min}$. Amplified products $(5 \mu \mathrm{L})$ were fractionated on $1.5 \%$ agarose gels, stained with Gelred and photographed under UV light (Wang et al., 2009).

\section{Data analysis}

ISSR and SSR bands were scored as present (1) or absent (0). Only the clearest and strongest reproducible bands were scored and used for the analysis. Among them, different ISSR phenotypes were put into the POPGENE program version 1.32 (Yeh et al., 1997). The following indices were used to quantify the amount of genetic variability between the 34 genotypes: percentage of polymorphic bands (PPB), observed number of alleles $\left(N_{\mathrm{A}}\right)$, effective number of alleles $\left(N_{\mathrm{E}}\right)$, Nei's gene diversity $(h)$, and Shannon information index $(I)$.

The NTSYS-pc software ver. 2.11 (Rohlf, 2004) was used to calculate Nei's similarity coefficients between all the samples based on the combined data of SSR and ISSR markers. Similarity matrices were used to construct the unweighted pair group method with arithmetic average (UPGMA) dendrograms within the SAHN module of the NTSYS program.

\section{RESULTS}

\section{Levels of polymorphism and discriminating capacity of the assays}

The results of two molecular assays in the fingerprinting of the 34 samples are presented in Tables 2 and 3. In the SSR method, a total of 43 bands were amplified by the 10 primers of which all were polymorphic $(100 \%)$. In this assay, the total number of bands was between 4 and 5 with an average of 4.3. Among the SSR loci, the primers Aprigms18, Pchgms4, and Bppct025 generated the higher number of bands (5 bands), while the other primers had the lower ones (4 bands) (Figure 1).

\begin{tabular}{|c|c|c|c|c|c|}
\hline Primer & Primer sequence $\left(5^{\prime} \rightarrow 3^{\prime}\right)$ & Total bands & PB & PPB & Annealing $\mathrm{T}\left({ }^{\circ} \mathrm{C}\right)$ \\
\hline Aprigms18 & $\begin{array}{l}\text { F: TCTGAGTTCAGTGGGTAGCA } \\
\text { R: ACAGAATGTGCGTTGCTTTA }\end{array}$ & 5 & 5 & 100 & 55 \\
\hline UDP98-405 & $\begin{array}{l}\text { F: ACGTCATGAACTGACACCCA } \\
\text { R: GAGTCTTTGCTCTGCCATCC }\end{array}$ & 4 & 4 & 100 & 58 \\
\hline UDP98-406 & $\begin{array}{l}\text { F: TCGGAAACTGGTAGTATGAACAGA } \\
\text { R: ATGGGTCGTATGCACAGTCA }\end{array}$ & 4 & 4 & 100 & 58 \\
\hline UDP98-409 & $\begin{array}{l}\text { F: GCTGATGGGTTTTATGGTTTTC } \\
\text { R: CGGACTCTTATCCTCTATCAACA }\end{array}$ & 4 & 4 & 100 & 57 \\
\hline UDP98-411 & $\begin{array}{l}\text { F: AAGCCATCCACTCAGCACTC } \\
\text { R: CCAAAAACCAAAACCAAAGG }\end{array}$ & 4 & 4 & 100 & 56 \\
\hline Pchgms4 & $\begin{array}{l}\text { F: ATCTTCACAACCCTAATGTC } \\
\text { R: GTTGAGGCAAAAGACTTCAAT }\end{array}$ & 5 & 5 & 100 & 54 \\
\hline Pchgms5 & $\begin{array}{l}\text { F: CGCCCATGACAAACTTA } \\
\text { R: GTCAAGAGGTACACCAG }\end{array}$ & 4 & 4 & 100 & 54 \\
\hline Bppct007 & $\begin{array}{l}\text { F: TCATTGCTCGTCATCAGC } \\
\text { R: CAGATTTCTGAAGTTAGCGGTA }\end{array}$ & 4 & 4 & 100 & 56 \\
\hline Bppct025 & $\begin{array}{l}\text { F: TCCTGCGTAGAAGAAGGTAGC } \\
\text { R: CGACATAAAGTCCAAATGGC }\end{array}$ & 5 & 5 & 100 & 58 \\
\hline Bppct030 & $\begin{array}{l}\text { F: AATTGTACTTGCCAATGCTATGA } \\
\text { R: CTGCCTTCTGCTCACACC }\end{array}$ & 4 & 4 & 100 & 57 \\
\hline Average & & 4.3 & 4.3 & 100 & \\
\hline
\end{tabular}

$\mathrm{PB}=$ polymorphic bands; $\mathrm{PPB}=$ percentage of polymorphic bands. 


\begin{tabular}{|c|c|c|c|c|c|c|c|c|c|}
\hline Primer & Primer sequence $\left(5^{\prime} \rightarrow 3^{\prime}\right)$ & Total bands & PB & PPB & Annealing $\mathrm{T}\left({ }^{\circ} \mathrm{C}\right)$ & $N_{\mathrm{A}}$ & $N_{\mathrm{E}}$ & $\mathrm{h}$ & $I$ \\
\hline UBC825 & ACACACACACACACACT & 8 & 6 & 75.00 & 52 & 1.7500 & 1.4447 & 0.2624 & 0.3951 \\
\hline UBC834 & AGAGAGAGAGAGAGAGYT & 7 & 6 & 85.71 & 55 & 1.7969 & 1.4347 & 0.2548 & 0.3907 \\
\hline UBC840 & GAGAGAGAGAGAGAGAYT & 6 & 5 & 83.33 & 52 & 1.8333 & 1.4691 & 0.2861 & 0.4342 \\
\hline UBC841 & GAGAGAGAGAGAGAGAYC & 9 & 9 & 100.00 & 54 & 2.0000 & 1.6036 & 0.3503 & 0.5200 \\
\hline UBC842 & GAGAGAGAGAGAGAGAYG & 7 & 4 & 57.14 & 52 & 1.5714 & 1.3238 & 0.1850 & 0.2731 \\
\hline UBC847 & CACACACACACACACARC & 7 & 5 & 71.43 & 52 & 1.7143 & 1.3771 & 0.2314 & 0.3550 \\
\hline UBC 850 & GTGTGTGTGTGTGTGTYC & 8 & 5 & 62.50 & 47 & 1.6250 & 1.3625 & 0.2177 & 0.3284 \\
\hline UBC856 & ACACACACACACACACYA & 8 & 5 & 62.50 & 42 & 1.6250 & 1.3565 & 0.2208 & 0.3346 \\
\hline UBC860 & TGTGTGTGTGTGTGTGRA & 7 & 5 & 71.43 & 52 & 1.7143 & 1.3127 & 0.2027 & 0.3170 \\
\hline Average & & 7.4 & 5.5 & 74.34 & & 1.7367 & 1.4094 & 0.2757 & 0.3720 \\
\hline
\end{tabular}

$\mathrm{PB}=$ polymorphic bands; $\mathrm{PPB}=$ percentage of polymorphic bands; $N_{\mathrm{A}}=$ number of alleles; $N_{\mathrm{E}}=$ effective number of alleles; $\mathrm{H}=$ Nei's gene diversity; $\mathrm{I}=$ Shannon information index.

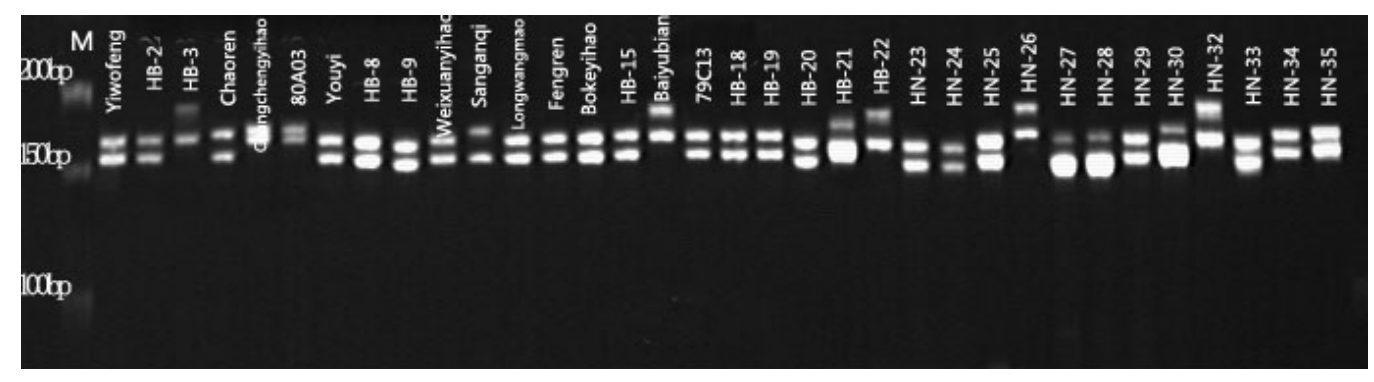

Figure 1. Amplification products for 34 samples by the SSR primer Bppct030. Lane $M=1-\mathrm{kb}$ DNA ladder.

In ISSR analysis, a lower level (74.34\%) of polymorphism was obtained, compared to the SSR method. Among them, the primer UBC841 detected the highest polymorphism $(100 \%)$ and the primer UBC842 detected the lowest polymorphism (57.14\%). A total of 67 bands were revealed by 9 ISSR primers based on clarity and specificity, with an average of 7.4 bands per locus. Among the ISSR loci, the highest polymorphism was observed with primer UBC841 (9 bands), while the lowest one was with primer UBC840 (6 bands). The average $N_{\mathrm{A}}$ and $N_{\mathrm{E}}$ were 1.7367 and 1.4094 , respectively. $h$ for individual loci varied from 0.1850 (UBC842) to 0.3503 (UBC841) with an average of 0.2757 , and the $I$ value was from 0.2731 (UBC842) to 0.5200 (UBC841) with an average of 0.3720 (Figure 2).

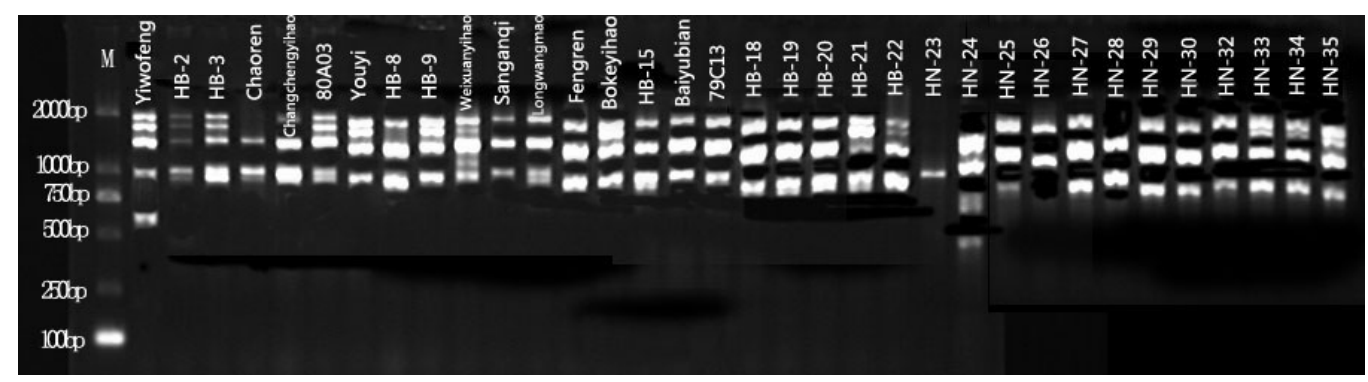

Figure 2. Amplification products for 34 samples by the ISSR primer UBC860. Lane $M=2-\mathrm{kb}$ DNA ladder. 


\section{Clustering and genetic relationships among 34 genotypes}

A total of 110 polymorphic bands were analyzed for genetic similarity coefficient (GSC) between the 22 sweet kernel apricot accessions and 12 cultivars in China. The results showed that genetic relationships were relatively distant between the 34 samples in this study. GSC ranged from 0.62 to 0.99 on the basis of the combined data of the SSR and ISSR molecular markers. The closest genetic relationship was between HB-18 and HB-20 with GSC of 0.99 , and the farthest genetic relationship was between HB-3 and HN-25 with GSC of 0.62. GSC of most varieties was from 0.7 to 0.8 . The 34 samples were clearly classified into three distinct major groups through cluster analysis based on GSC: Changchengyihao and HB-3 each as one cluster, and the other samples as the third cluster (Figure 3).

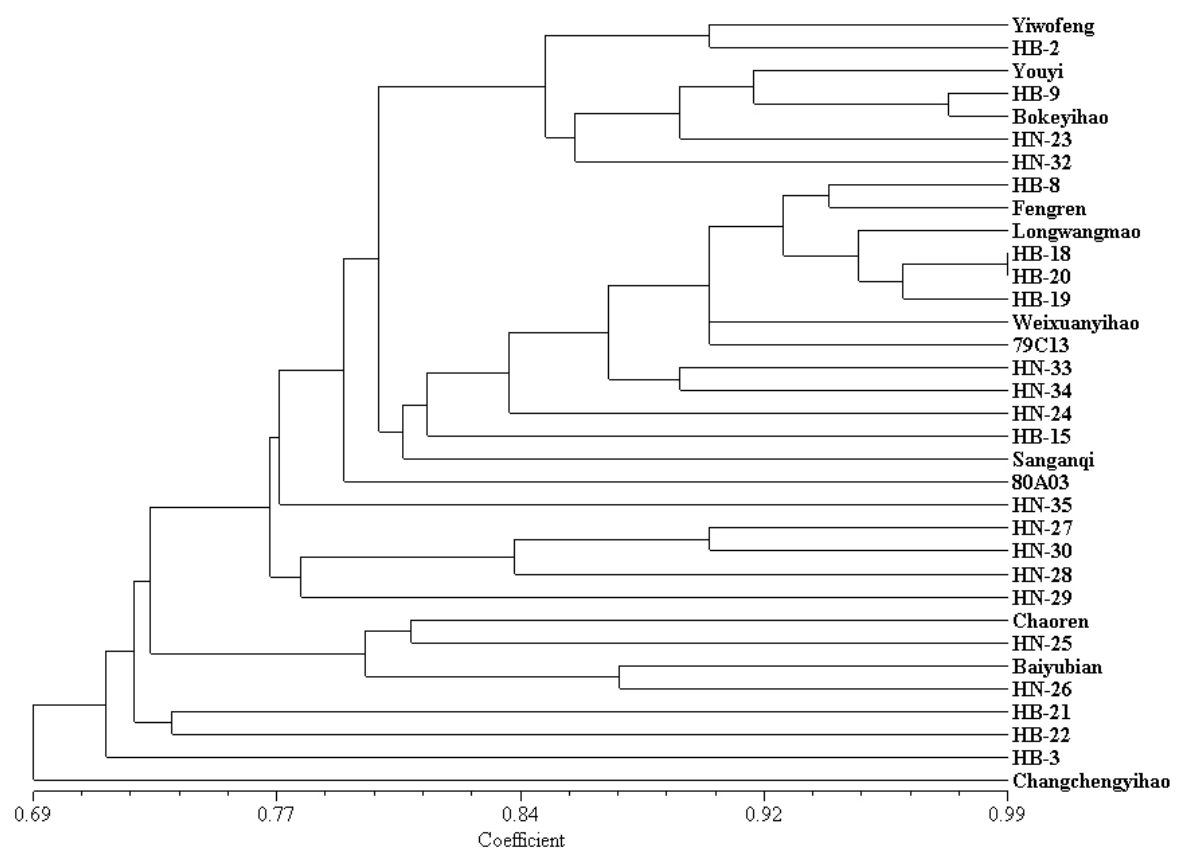

Figure 3. UPGMA cluster for 34 varieties based on combined data of SSR+ISSR markers.

\section{DISCUSSION}

Considerable research has been on the genetic relationship of Armeniaca Scop. in recent years, but the genetic relationship of the sweet kernel apricot germplasm resources was the first study. In SSR analysis, a higher level (100\%) of polymorphism than with ISSR method was detected (74.34\%), which could be attributed to the significantly lower number of SSR alleles analyzed. The values of microsatellite variation in the sweet kernel apricot germplasm resources were greatly higher than in other species of Armeniaca Scop. in China using SSR molecular markers. The polymorphism level of SSR used in this study was higher than in the study of $\mathrm{He}$ et al. (2006) $(\mathrm{PPB}=84.9 \%)$ and Liu et al. $(2013)(\mathrm{PPB}=93.0 \%)$. However, 
the polymorphism level of ISSR was lower than that reported by Feng et al. (2005) (PPB = $90 \%)$ and Xie et al. (2011) (PPB $=96.5 \%)$. In ISSR analysis, $h$ with an average of 0.2757 and $I$ with an average of 0.3720 showed that there was abundant genetic diversity between the sweet kernel apricot germplasm resources.

The UPGMA dendrogram showed a relatively far relationship between 22 sweet kernel apricot accessions and 12 cultivars based on the GSC range from 0.62 to 0.99 . There was no clear separation of the varieties according to their collection location, perhaps because the resources of Luoyang, Henan Province, were introduced from Zhuolu Hebei Province. The 34 samples were classified into three distinct major groups on the basis of GSC: Changchengyihao and HB-3 each one cluster, and the other samples as the third cluster. The results showed that genetic relationship was distant between HB-3 and Changchengyihao and the other species, maybe because HB-3 and Changchengyihao were early in evolution. We should pay more attention to them and use them in breeding new varieties. Meanwhile, there was a close genetic relationship between HB-18 and HB-20 with GSCs 0.99 , which showed that they were maybe the same variety. We should check them according to morphological characters.

As an important economic forest tree species, loss of genetic diversity could not support enough breeding resources for the development of sweet kernel apricot germplasm resources. Meanwhile, the information on the levels and distribution of genetic diversity was important for designing conservation strategies for this species. Therefore, it was necessary to study the genetic relationship and genetic diversity for its genetics and breeding research.

\section{ACKNOWLEDGMENTS}

Research supported by the "Twelfth Five Year" Plan key projects of the National Science and Technology of China (Grant \#2013BAD14B00). We would like to extend our sincere thanks to Prof. Zhi-Qiang Sun for his valuable comments to improve this manuscript. We are especially grateful to the editors and reviewers for their valuable suggestions.

\section{REFERENCES}

Bassil N and Postman JD (2010). Identification of European and Asian pears using EST-SSRs from Pyrus. Genet. Resour. Crop Evol. 57: 357-370.

Celyon J, Tustin D, Chagné D and Gardiner S (2008). Construction of a dense genetic linkage map for apple rootstocks using SSRs developed from Malus ESTs and Pyrus genomic sequences. Tree Genet. Genomes 2: 86-97.

Dreisigacker S, Zhang P, Warburton ML, Van Ginkel M, et al. (2004). SSR and pedigree analyses of genetic diversity among CIMMYT wheat lines targeted to different megaenvironments. Crop Sci. 44: 381-388.

Feng CJ, Zhang YH, Xu XY, Shi GH, et al. (2005). Genetic diversity revealed by ISSR marker in apricot. J. Agric. Univ. Hebei 28: 52-56. (in Chinese).

Garkava-Gustavsson L, Mujaju C, Sehic J, Zborowska A, et al. (2013). Genetic diversity in Swedish and Finnish heirloom apple cultivars revealed with SSR markers. Sci. Hortic. 162: 43-48.

Gillaspie AG, Hopkins MS and Dean RE (2005). Determining genetic diversity between lines of Vigna unguiculata subspecies by AFLP and SSR markers. Genet. Resour. Crop Evol. 52: 245-247.

Hailu F, Merker A, Belay G and Johansson E (2005). Molecular diversity and phylogenic relationships of tetraploid wheat species as revealed by inter-simple sequence repeats (ISSR) from Ethiopia. J. Genet. Breed. 59: 329-337.

He TM, Chen XS, Gao JS, Zhang DH, et al. (2006). Using SSR markers to study population genetic structure of cultivated apricots native to Xinjiang. Acta Hortic. Sin. 33: 809-812. (in Chinese).

Hurtado MA, Badenes ML and Llácer G (1999). Random amplified polymorphic DNA markers as a tool for apricot cultivar identification. Acta Hort. 488: 281-287.

Jain S, Jain RK and McCouch SR (2004). Genetic analysis of Indian aromatic and quality rice (Oryza sativa L.) germplasm 
using panels of fluorescently-labelled microsatellite markers. Theor. Appl. Genet. 109: 965-977.

Khlestkina EK, Röder MS, Efremova TT, Börner A, et al. (2004). The genetic diversity of old and modern Siberian varieties of common spring wheat as determined by microsatellite markers. Plant Breed. 123: 122-127.

Liu BY, Li YY, Tang YC, Wang LY, et al. (2010). Assessment of genetic diversity and relationship of tea germplasm in yunnan as revealed by ISSR markers. Acta Agronom. Sin. 36: 391-340. (in Chinese).

Liu MP, Fu DL, Fu JM and Tian M (2011). A new DNA band display technology of microsatellite DNA. Afr. J. Biotechnol. 10: 19276-19279.

Liu HG, Zhang LS and Hu JF (2013). Genetic diversity of apricot three ecological group by SSR analysis. China Fruits 1: 13-16. (in Chinese).

Maguire TL, Peakall R and Saenger P (2002). Comparative analysis of genetic diversity in the mangrove species Avicennia marina (Forsk.) Vierh. (Avicenniaceae) detected by AFLPs and SSRs. Theor. Appl. Genet. 104: 388-398.

Marotti I, Bonetti A, Minelli M, Catizone P, et al. (2007). Characterization of some Italian common bean (Phaseolus vulgaris L.) landraces by RAPD, semi-random and ISSR molecular markers. Genet. Resour. Crop Evol. 54: 175-188.

Piquemal J, Cinquin E, Couton F, Rondeau C, et al. (2005). Construction of an oilseed rape (Brassica napus L.) genetic map with SSR markers. Theor. Appl. Genet. 111: 1514-1523.

Powell W (1997). Locating genotypes and genes for abiotic stress tolerance in barley: a strategy using maps, markers and the wild species. New Phytol. 137: 141-147.

Rohlf JF (2004). NTSYS-pc: 2.11 Numerical Taxonomy and Multivariate Analysis System. Exeter Software, Setauket.

Saghai-Maroof K, Soliman M, Jorgensen RA and Allard RW (1984). Ribosomal DNA spacer-length polymorphisms in barley: Mendelian inheritance, chromosomal location, and population dynamics. PNAS 81: 8014-8018.

Tautz D (1989). Hypervariability of simple sequences as a general source for polymorphic DNA markers. Nucleic Acids Res. 17: 6463-6471.

Wang ZY, Yuan XJ, Guo HL and Liu JX (2009). Optimization of ISSR-PCR system on Zoysia spp. Acta Pratacult. Sin. 17: 48-51. (in Chinese).

Xie J, Guo TJ, Li F, Zhang YB, et al. (2011). ISSR analysis of 92 apricot germplasm resources. China Fruits 2: 14-18. (in Chinese).

Xie RJ, Li XW, Chai ML, Song LJ, et al. (2010). Evaluation of the genetic diversity of Asian peach accessions using a selected set of SSR markers. Sci. Hortic. 125: 622-629. (in Chinese).

Yeh FC, Yang RC, Boyle TBJ, Ye ZH, et al. (1997). POPGENE, the user-friendly shareware for population genetic analysis. Molecular Biology and Biotechnology Centre, University of Alberta, Edmonton.

Zhang YR, Luo JC and Yu JX (2007). Genetic diversity of the endangered plant Abies ziyuanensis detected by ISSR markers. J. Beijing Forestry Univ. 29: 41-46. (in Chinese). 